\title{
Employers’ Feedback on Business Graduates
}

\author{
Arpita Mehrotra \\ Royal University of Bahrain, \\ West Riffa, Kingdom of Bahrain
}

\author{
Hala Elias \\ Royal University for Women (RUW), \\ West Riffa, Kingdom of Bahrain
}

\begin{abstract}
The current market trend is that companies look for graduates with diverse skills ranging from critical to soft skills. Due to high demand of skilled graduates by the employers, educators are greatly concerned of the quality of graduates churned out by the university. This paper attempts to investigate how well the business graduates of a private university in the Kingdom of Bahrain are prepared through measuring the level of satisfaction of employers towards recruiting business graduates of the Royal University for Women (RUW). The study investigated 40 organizations across the public and private sectors that have provided job opportunities to RUW business graduates. The findings suggested that communication skills (in terms of oral and written) were rated as the most important skills for graduates. Bahraini employers expressed that they gave more importance on the graduate's soft skills and team working rather than their personal attributes. In general, the findings of the employer satisfaction survey present a positive picture for RUW business graduates. It appears that employers are satisfied with the education graduates receive and would hire additional graduates in the future. In addition, negotiation skills and analytical and critical thinking skills were also high-rate in terms of satisfaction. The findings were useful in identifying gaps that exist in the quality of skills among business graduates and employers' requirements.
\end{abstract}

Keywords: business graduates, skills and attributes, employers’ feedback

\section{Introduction}

Organizations are continuously employing graduates to raise their scholarly capital to enable growth and constant innovation is deemed to be a wise decision (McDermott, Mangan, \& O’Connor, 2006). In general, employers need graduates to be able to function in the workplace, be confident communicators, good team-players, critical thinkers, problem-solvers, and to be adaptive and adaptable to new challenges and workplace changes (Harvey, Locke, \& Morey, 2002; Pearson, 2001). Graduates’ technical know-how is already a default factor that enables them to be employed. However, the soft skills are equally important for graduates to use their technical skills more effectively (Nasir, Ali, Noordin, \& Nordin, 2011).

The relationship between quality of skills possessed by university graduates and the job market has been the focus of growing theoretical and empirical investigations in the education literature (Duoc \& Mertzger, 2006). The central issue in this literature is to examine employers' perceptions about the quality of university graduates in terms of their hard and soft skills. Empirical studies revealed that employers place great emphasis on graduates' soft skills, and their ability to deal empathetically and effectively with job's demands. Soft skills assist graduates in progressing and maintaining their jobs.

Arpita Mehrotra, Dr., assistant professor, College of Business and Financial Sciences, Royal University of Bahrain. Hala Elias, Dr., associate professor, College of Business and Financial Sciences, Royal University for Women (RUW). 
Employers complain that most of the graduates lack necessary core skills need to be succeeded at work and need for their future career. Hence, universities together with educational authorities need to work together and to adopt strategies that tackle skills deficits and match universities inputs with employers and businesses demand (Ranasinghe \& Herath, 2011). In other words, academics and educational authorities need to work closely with employers to ensure that university graduates possess skills that satisfy the market needs. It is, therefore, of vital importance to explore the main factors that employers expect graduates to possess to enhance their employability chances.

There is limited body of empirical studies about employers' perceptions towards the quality of university graduates in the Gulf Cooperation Council (GCC) region (Al-Mutairi, Naser, \& Saeid, 2014). Therefore, the purpose of this study is to identify the skills which employers in the Kingdom of Bahrain require when recruiting business graduates. It is expected that the outcome of this study will assist the university management in formulating their education strategies in a way that assists in satisfying the market demand.

The objectives of the study include the following:

1. Assessing the extent of employer satisfaction with the soft skills of Royal University for Women (RUW) business graduates;

2. Assessing the extent of employer satisfaction with the technical skills of RUW business graduates;

3. Identifying which skills RUW business graduates are lacking;

4. Determining which skills employers are seeking when recruiting new graduates.

\section{Literature Review}

According to Duoc and Mertzger (2006), for several years, educators, employers, and university administrators had been greatly concerned about the quality of graduates, because those graduates had less demand in the labor market. Therefore, the number of research had been done addressing the employability, quality of graduates, and satisfaction levels of employers towards graduates.

There are various definitions of employability skills as defined by the scholars, such as the basic skills necessary for getting, keeping, and doing well in a job, and which cut horizontally across all industries and vertically across all jobs (Harvey \& Green, 1994; McDermott, 2006). It is also defined as skills required not only to gain employment, but also to progress within an enterprise in order to achieve one's potential and contribute successfully to enterprise strategic directions (Murray \& Robbinson, 2001). This is due to the rapid changes taking place in the economy, which create pressures on employers to identify and recruit graduates who possess critical employability skills relevant to current demands.

Graduate employability is an important aspect of higher education industry. It evaluates the success and ability of the particular institution in producing work ready graduates. Employability has been used as a performance indicator for higher education institutions (HIEs). Harvey (2001) had defined employability in various ways from individual and institutional perspectives. Individual employability is defined as graduates being able to demonstrate the attributes to obtain jobs. Commonly, institutional employability relates to the employment rates of the university graduates. Prior to this, Harvey and Howard (1999) suggested that graduates' success in their jobs depended more on graduates attributes than on narrow discipline specific degrees. Furthermore, Barrie (2004) indicated that the generic graduate attributes would directly relate the graduate outcomes to the employability. 
According to Yorke and Knight (2006), employability skills were the potential a graduate had for obtaining and succeeding in graduate level. They suggested that employability aspects could be categorized into: Person qualities (e.g., self-awareness and self-confidence), core skills (e.g., critical analytic and creativity), and process skills (e.g., computer's application and coping with complexity). These skills became as a vehicle for graduates to transfer to the labor market. Further, Al-Alawneh (2014) stated that employability was better thought of in terms of personal transitions between different activities, each with their own culturally contingent knowledge bases, rather than as the deployment of general skills or qualities. Employability can more accurately be thought of as an interaction between the person and the contexts in which they operate. As such, employability can be thought of as a quality of workplaces as well as people.

Saterfiel and Maclarty (1995) said that graduates' employability referred to those skills graduates need to get and keep jobs (Yusof \& Jamaluddin, 2015) through learning new skills for different functions as demanded by employers or industry. Harvey (2001) defined graduate employability as the ability of graduate to display the qualities needed by the employer for the organizations future requirements. Employability skills are a set of achievement, understanding, and personal attitudes/qualities that mark the individual as potentially more able to get desired job and successful in career choice. Generally, employability skills are those aspects of skills and knowledge students need to have to equip them to fulfill various employment demands in the labor market after they have completed their studies. The development graduates' employability aspects are an important core in higher learning to enable them to be gainfully employed in the job market. In addition to the knowledge skills, employers also demand good personality from graduates. Among the important factors to be considered are the ability to adapt to the culture of the firm and the desire to learn continuously (Cai, 2012).

Recently, there is more focus by many HIEs on graduates' employability. According to Ausin (2010), universities were taking, in the last decade, complementary roles in teaching and learning, research, and innovation. Effectiveness in universities education today is seen not only from the skills of their students, but also from other more pragmatic aspects, such as job placement rates and professional students. Employability is about how individuals engage with opportunities, and reflect and articulate their skills and competencies (Harvey, Locke, \& Morey, 2002; Al-Alawneh, 2014).

In the UK, employability remains high on the agenda for the HEIs. It was noted (Rae, 2007) that it was important to analyze the curriculum through the institutional connectivity. This is part of the challenge, as the connectivity would involve all the higher education stakeholders (students, staffs, and employers). A study conducted in China (Guo \& Beatrice, 2008) reported that most educational institutions were trying to expand students' knowledge from not just the book view but moving towards providing the "employability skills.” As such, the curriculum has been re-designed where the first two years of education and the students will be exposed to general business curricula. The last two years, the students were exposed with the subspecialty curricula.

A study conducted for marketing courses highlighted that problem-solving skills is important to prepare students to capitalize on opportunities afforded by case-based capstone courses and to better meet the needs and expectations of prospective employers (Diamond et al., 2008). Also, Hodges and Burchell (2003) surveyed New Zealand employers' views of how well business graduates were prepared for the workplace. They found that employers place a great emphasis on graduates' soft skills, their ability to deal empathetically and effectively with job demand. They provided evidence that employers believed graduates had unrealistic expectations of life in the business world, and were generally deficient in interpersonal skills. Hodges and 
Burchell (2003) recommended that cooperative education programs could help students to understand that the workplace was a place where they must take responsibility for identifying their own learning needs and then do something about it. Andrews and Higson (2008) explored employer perspectives of business graduate employability in four European countries (UK, Austria, Slovenia, and Romania). They found that there are notable similarities in employer perspectives of what may be termed "core components" of business graduate employability. The core components include the value of hard business-related knowledge and skills, the importance of soft business-related skills and competencies, and the need for prior work-experience.

On the other hand, Ting and Ying (2012) revealed that practitioners and academicians had similar perception on the importance of business graduates' competencies regarding written skills, oral skills, research skills, knowledge-acquiring skills, honesty, diligence, resourcefulness, value-improving, teamwork ability, innovative skills, and computer skills. MdSaad, Robani, Jano, and Majid (2013) found that problem-solving, tool handling competency and presentation skills were highly featured amongst the skills demanded of graduates by employers. MdSaad et al. (2013) added that an employee, who possessed the ability to think critically, act logically, and evaluate situations to make decisions and solve problems, was a valuable asset to the organization. Rasul, Rauf, and Mansor (2013) pointed out that employers placed great importance to interpersonal skills, thinking skills, and personal qualities that students needed to emphasize to be employed in the manufacturing sector. They also provided evidence that employers' stress that every position in any size of industry requires some kind of teamwork.

A study by Salleh, Yusoff, Harun, and Memon (2015) focused on identifying the soft skills of graduate architects deemed important by the industry and to gauge their satisfaction with the level of skills possessed by the graduates. The results of a survey of professional/senior architects from 65 architectural firms suggested that proficiencies in English language (in terms of oral, written, oral presentation, and written presentation) were rated as most important skills for graduate architects. The findings further revealed that the employers were least satisfied with the graduates' negotiation skills and analytical and critical thinking. The findings were useful in recognizing employers' expectations of soft skills and identifying gaps that exist in the quality of soft skills among graduate architects.

Saad and Majid (2014) conducted a survey of 299 Malaysian employers from diverse types of agencies and organizations, which employ engineering, and information and communication technology (ICT) graduates. Their findings revealed that problem-solving, tool-handling competency, presentation skills, and team-working skills feature highly amongst the employers as important skills demanded from the students. While in Tunisia, Klibi and Oussii (2013) analyzed students' perceptions about the skills set required, and tried to bring them closer to employers' expectations. They found that employers emphasized the need for graduates to develop generic skills related to ethical awareness, communication, critical analysis, and teamwork. They concluded that universities have to develop coherent policies and frameworks to promote cognitive intelligence, social, vocational, and personal development.

E. Ramadi, S. Ramadi, and Nasr (2015) explored the gaps between industry expectations and perceptions of engineering graduates' skill sets in the Middle East and North Africa region. They measured the importance that managers of engineers placed on 36 skills relevant to engineers. Results showed significant gaps between managers' expectations of and satisfaction with all 36 skills. The managers felt that graduates needed most improvement of communication, time management, and continuous learning. Managers reported that recent engineering graduates exhibited low overall preparedness for employment. Ngoo, Tiong, and Pok (2015) found 
that employers demanded a more independent and leader instead of a follower, and a more management prone graduates. The soft skills of communication skills, critical thinking and problem-solving skills, ethics and professional moral skills, leadership skills, lifelong learning and informational management skills, and teamwork skills, while the technical skills of financial accounting, management accounting, taxation, auditing, and information system are suggested.

On the other hand, few studies were undertaken in GCC region to investigate employers' perception about the quality of university's graduates. For instance, El-Sakran and Awad (2012) conducted semi-structured interviews to find out employability skills demanded by United Arab Emirates (UAE) engineering companies' employers from new recruits. They found there are deficiencies in fresh engineering graduates' oral and written communication skills and some other personal attributes. El-Sakran and Awad (2012) suggested that colleges of engineering in non-English speaking countries should recognize the fact that English fluency was a necessary condition for success in a global economy. Thus, a strong emphasis should be placed on developing excellence in communication skills, both written and oral, an important issue that should be accorded extra focus in non-English speaking countries.

In addition, Al-Mutairi, Naser, and Saeid (2014) conducted a study to explore factors considered by employers when recruiting business graduates in Kuwait. Four categories of employability factors were used in the study covering graduates' knowledge, soft skills, personal abilities, and working with groups. The results of the analysis revealed that participants attach the highest level of importance to graduates' knowledge, soft skills, and ability to work within groups. The participants attach low-level of importance to the personal abilities of the graduates. The study concluded that employability factors are affected by employers' background characteristics, the firm's nature, size, and ownership (whether family, public, or government). The authors also pointed out that in a country, like Kuwait, employability factors were governed by cultural and social considerations.

Therefore, the above studies reveal that employability is a difficult concept to measure and to define. Employability concept appears to grow in line with the changes in work pattern and manpower model. McQuaid and Linda (2005) stated that although employability was a vague concept in the past decade, it now played an important role in determining the UK labor market policy, in some European countries, and other countries. Employability now is looked upon as the main target in most labor market policies and manpower strategies in most country especially for the employability of graduates (Yusof \& Jamaluddin, 2015). Therefore, universities are under intense pressure from their stakeholders, especially industry, to equip graduates with more than just academic skills. The failure of universities to deal with this issue could create an unnecessary negative perception, which could lead industries becoming more selective in recruiting capable and competent graduates to work for them.

\section{Research Methodology}

\section{Research Design}

This study was mainly a quantitative research that uses descriptive approach using common statistical tools such as descriptive statistics, cross-tabulations, and one-way analysis of variance (ANOVA) test for data analysis. The data were analyzed using statistical package for social sciences (SPSS) version 21. Cronbach alpha coefficients were calculated to examine the reliability of the scale used. Mean scores and standard deviations were used to analyze the data of the study. 


\section{Sampling}

The study was based on the sample of employers from private and public sector in the Kingdom of Bahrain and Saudi Arabia. Out of the 164 surveys that were e-mailed to the RUW graduates' employers, 65 were successfully collected having a response rate of $40 \%$. The study selected graduates' supervisors or line managers that mentored the graduates in the period of their work. The questions in the survey included demographic information of the graduates from the College of Business and Financial Sciences, the satisfaction rating of the supervisor on the employees based on their knowledge and understanding skills, critical-thinking skills, general skills, and general qualities.

The questions that include the style of rating is an important satisfaction method where the employers are able to rate their satisfaction upon the performance of the employees. Moreover, the employer has the chance to rate the business graduates on a scale of one to five.

\section{Method of Data Collection}

The employers' satisfaction survey was either sent directly to the employers of the graduates or the graduates were contacted to facilitate the process of reaching the employers. For this purpose, the study used two main research instruments as structured questionnaires and interviews. A structured questionnaire was used to collect data for the study. The respondents were asked to rate the importance and their satisfaction with various skills based on RUW graduate attributes on a 5-point Likert scale.

The data were analyzed using SPSS version 21. Cronbach alpha coefficients were calculated to examine the reliability of the scale used. With alpha coefficients of 0.89 for importance and 0.97 for satisfaction were found indicating the scale can be regarded as highly reliable to represent soft skills of the business graduates. Mean scores and standard deviations were used to analyze the data of the study. In interpreting the mean scores, the following were used: 4.21-5.00 ("Highly important”/“Highly satisfied”), 3.41-4.20 (“Important”/“Satisfied”), 2.61-3.40 (“Moderately important”/“Moderately satisfied”), 1.81-2.60 ("Not important”/“Not satisfied”), and 1.00-1.80 (“Not important at all”/“Not satisfied at all”).

The questionnaire included short answer questions, ranking questions, and open-ended questions. The survey asked employers to rate the importance of various skills to the position into which the graduate was hired, and then also rate their level of satisfaction on how the particular employee performs the skill. Items are ranked on a 5-point scale and mean scores are calculated for each skill's importance and satisfaction, with the resulting gap showing whether the employee is meeting expectation. Mean scores can be interpreted as: $1=$ "Not at all satisfied," 2 = "Not very satisfied," 3 = "Somewhat satisfied," 4 = "Very satisfied," and 5 = "Extremely satisfied." The survey asked about employee performance in four general areas: knowledge and understanding, qualities generally expected of employees, general skills, and specialized skills.

\section{Analysis of the Results}

\section{Employers' Satisfaction With the Soft Skills of RUW Business Graduates}

The mean scores for the employers' satisfaction on the RUW business graduates are shown in Table 1. The findings revealed that the employers were satisfied with the RUW business graduates' willingness to learn with the mean score of 4.56 and collegiality 4.27. The findings interestingly showed that the employers were least satisfied with the graduates' English languages abilities in terms of written presentation, written communication, and oral presentation. In addition, leadership skills and working independently were also low on the list in terms of satisfaction. 
Table 1

Employers' Satisfaction With the Soft Skills of RUW Business Graduates

\begin{tabular}{lll}
\hline Employers' satisfaction with soft skills items & Mean score & $S D$ \\
\hline Teamwork & 4.10 & 1.12 \\
Written communication & 3.80 & 0.88 \\
Oral communication & 3.95 & 0.88 \\
Time management & 4.02 & 0.98 \\
Positive attitude at work & 4.12 & 1.06 \\
Willingness to learn & 4.56 & 0.58 \\
Resolving conflicts/Handle different opinion & 4.07 & 0.80 \\
Works independently & 3.88 & 0.83 \\
Leadership skills & 3.80 & 1.11 \\
Problem solving skills & 4.26 & 1.01 \\
Collegial & 4.27 & 1.11 \\
Accountability & 4.01 & 1.16 \\
\hline
\end{tabular}

Employers' Satisfaction With the Technical Skills of RUW Business Graduates

The mean scores for the employers' satisfaction with the technical skills on the RUW business graduate were tabulated in Table 2. The findings revealed that RUW business graduates possess theoretical knowledge in the field of study and are able to translate theory into practice with the mean score of 4.35 and 4.13, respectively. The findings interestingly revealed that RUW business graduates lack specific computer application skills like excel and understanding of industry standards and practices with the mean score of 3.75 and 3.80 .

Table 2

Employers' Satisfaction With the Technical Skills of RUW Business Graduates

\begin{tabular}{lll}
\hline Employers' satisfaction with technical skills items & Mean score & $S D$ \\
\hline Possess theoretical knowledge in the field of study & 4.35 & 0.79 \\
Possess practical knowledge provided by the degree & 4.04 & 0.71 \\
Possesses knowledge of specific computer applications & 3.75 & 0.89 \\
Possesses an understanding of industry standards and practices & 3.80 & 0.88 \\
Translates theory into practice & 4.13 & 0.80 \\
\hline
\end{tabular}

\section{Skills Which RUW Business Graduates are Lacking}

Out of 17 important skills identified, 11 show a positive employer satisfaction levels. A gap score is calculated by measuring the difference between the importance mean and satisfaction mean. A negative gap indicates the employer's dissatisfaction with employee performance below the level of importance for the skill. The gap scores are tabulated in Figure 1. The three skills with the highest gap are knowledge of specific computer applications, written communication, and understanding of industry standards and practices with scores of $-0.27,-0.21$, and -0.10 , respectively. However, skills which have smaller gaps are knowledge in the field of study and willingness to learn. 


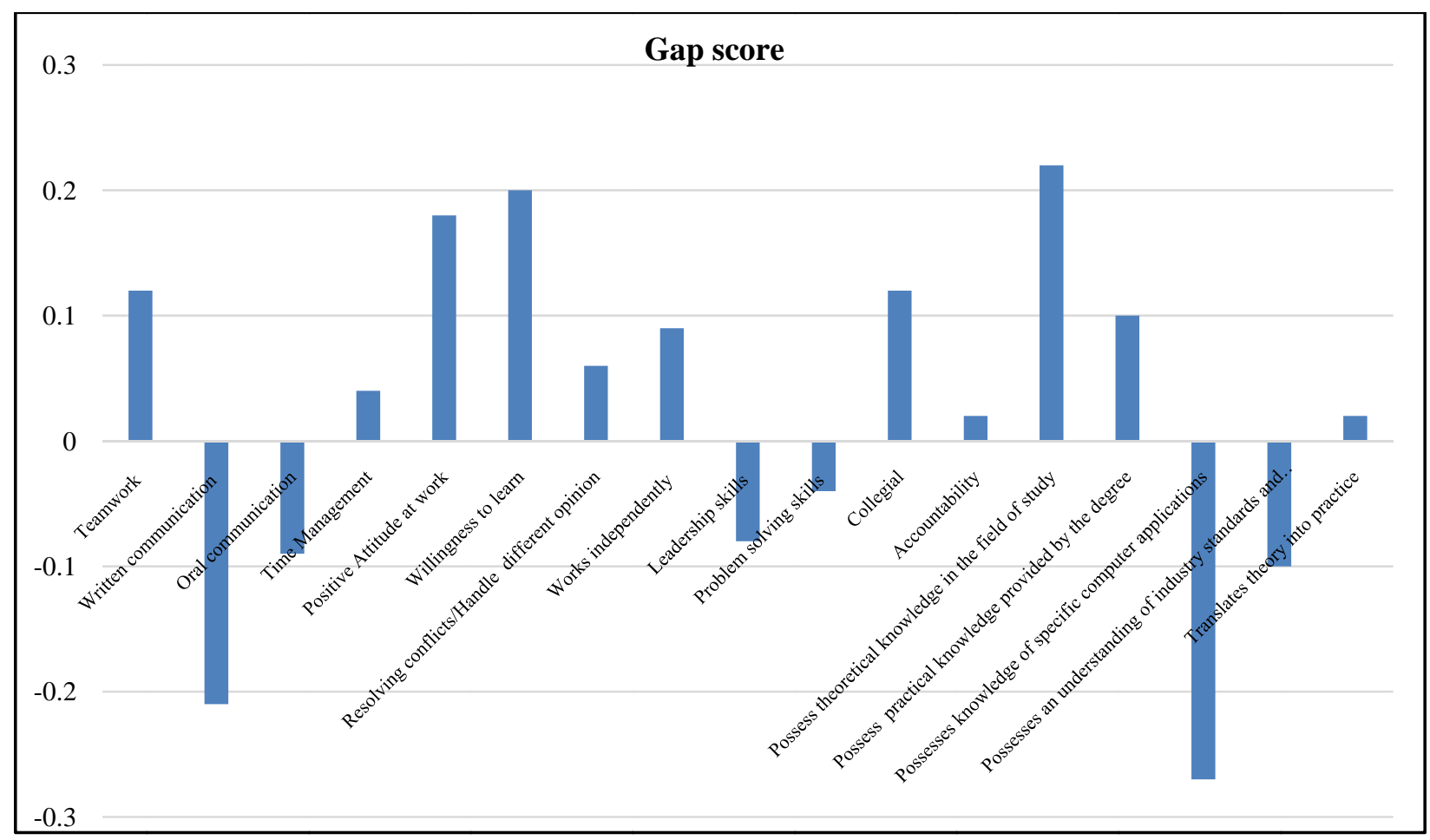

Figure 1. Skills RUW business graduates are lacking.

\section{Skills Which Employers Seek When Recruiting New Graduates}

The survey asked employers to rate six skills employers are seeking when recruiting new graduates. Figure 2 summarizes the important skills which were ranked on a 5-point scale $(1=$ "Not at all," $2=$ "Not very," $3=$ "Somewhat," 4 = "Very," and 5 = "Extremely"). The employer's rate understanding of technical knowledge required for the job and knowledge of computer applications as the most important skills to be considered for recruiting new graduates with scores of 4.78 and 4.25 , respectively.

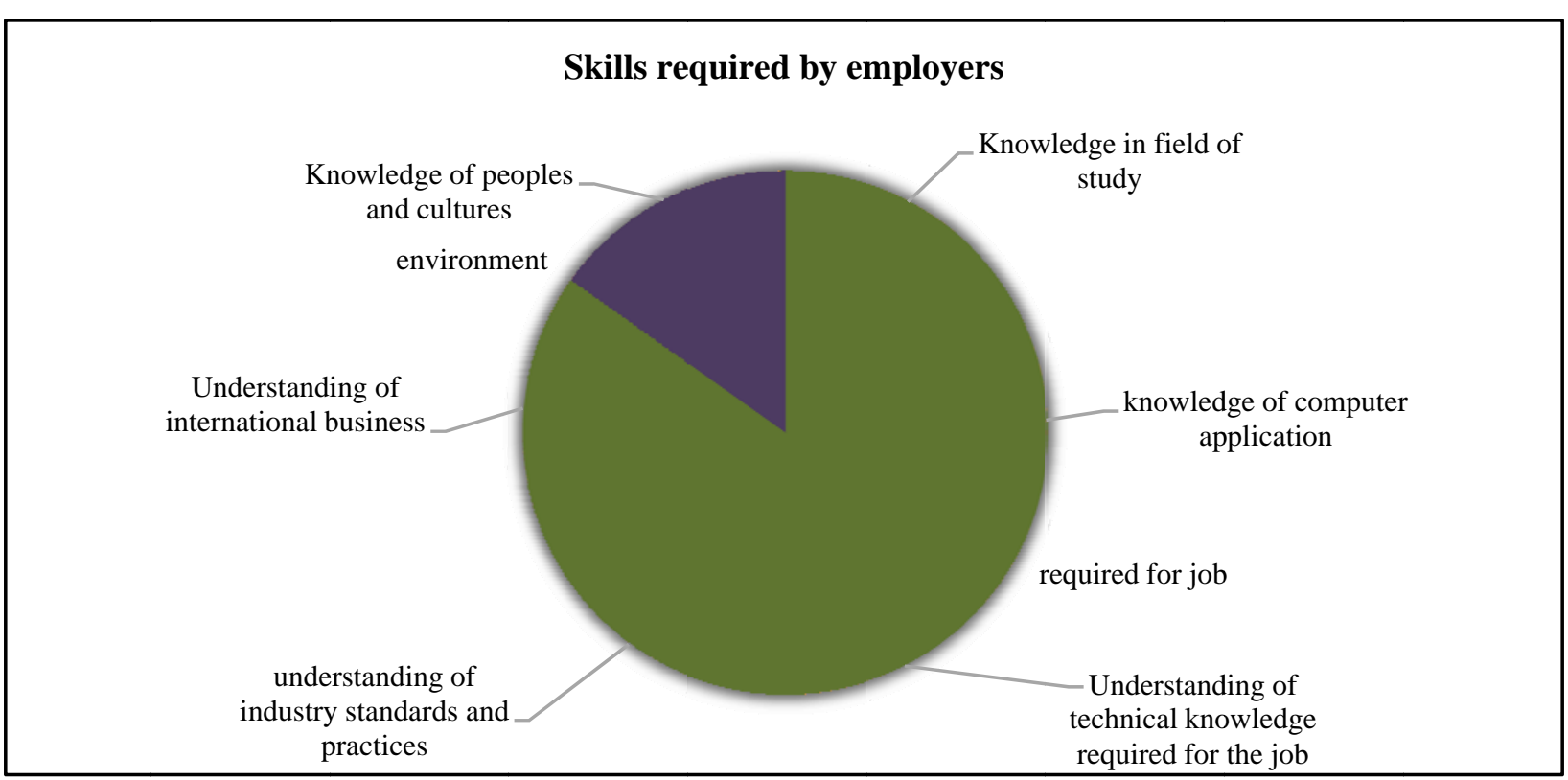

Figure 2. Skills employers seek when recruiting new graduates. 


\section{Conclusions}

Information gathered enabled the assessment of employer satisfaction of RUW business graduates. Previous studies show that employability skills are amongst the most important skills that employers require their potential employees to possess before recruiting them. The skills listed in the study as important skills which a business graduate should possess include the technical knowledge of the required job. The study also provides evidence that employers give more importance to skills like, computer applications due to innovation in technology which is being used as the most important tool to communicate in the organizations. Written communication skills and understanding of industry standards and practices are also listed as important skills in order to share the information effectively in the organization.

The findings of this study identified a set of factors for being employable. The study also provided important data which can be used for improving and developing business education. On the basis of the findings, RUW should equip its graduates with employability skills and work on bridging the gap between the employer expectation and professional competence of a business graduate. The skills and competencies need to be in accordance with the labor market and the economy's trends, such as expansion in financial services, regulatory environment, e-commerce, and complexity of international trade.

\section{References}

Al-Alawneh, M. (2014). Measuring students’ employability skills as they are perceived at Yarmouk University. Canadian Social Science, 10(1), 10-20.

Al-Mutairi, A., Naser, K., \& Saeid, M. (2014). Employability factors of business graduates in Kuwait: Evidence from an emerging country. International Journal of Business and Management, 9(10), 49-61.

Andrews, J., \& Higson, H. (2008). Graduate employability, “soft skills” vs. "hard” business knowledge: A European study. Higher Education in Europe, 33(4), 411-422.

Ausin, E. A. (2010). Employability of university: Learning orientation based on competencies. Spain: Universidad de Deusto. (ProQuest dissertations, UMI Publishing: 3493723)

Barrie, S. C. (2004). A Research-based approach to generic graduate attributes policy. Higher Education Research and Development, 23(3), 261-275.

Cai, Y. (2012). Graduate employability: A conceptual framework for understanding employers’ perceptions. Higher Education, 65(4), 457.

Diamond, A., Walkley, L., Forbes, P., Hughes, T., \& Sheen, J. (2008). Global graduates: Global graduates into global leaders. Leicester, England: AGF/CIHE/CFE. Retrieved July 15, 2016, from http://www.ucml.ac.uk/sites/default/files/shapingthe future/101/CIHE\% 20\%201111GlobalGradsFull.pdf

Duoc, T. Q., \& Mertzger, C. (2006). Quality of business graduates in Vietnamese institutions: Multiple perspective. Journal of Management Development, 26(7), 629-643.

El-Sakran, T., \& Awad, A. (2012). Voices from the United Arab Emirates: Engineering graduates' Labor market requisite competencies. American Journal of Engineering Education, 3(2), 105-114.

Guo, Z. W., \& Beatrice, van der H. (2008). Employability enhancement of business graduates in China: Reacting upon challenges of globalization and labor market demands. Education and Training, 50(4), 289-304.

Harvey, L. (2001). Defining and measuring employability. Quality in Higher Education, 7(2), 97-109.

Harvey, L., \& Green, D. (1994). Employer's satisfaction. Fifth QHE 24-Hour Seminar, Birmingham.

Harvey, L., \& Howard, H. (1999). Graduate employability audit. Cardiff Cyngor Cyllido Addysg Uwch Cymru/Higher Education Funding Council for Wales. Cymraeg: Sponsored by Welsh Assembly Government.

Harvey, L., Locke, W., \& Morey, A. (2002). Enhancing employability, recognizing diversity-Universities UK and CSU. Retrieved May 25, 2016, from http://www.qualityresearchinternational.com/esecttools/relatedpubs/enhancingemployability recdivers ity.pdf

Hodges, D., \& Burchell, N. (2003). Business graduate competencies: Employers' views on importance and performance. Asia Pacific Journal of Cooperative Education, 4(2), 16-22. 
Klibi, M., \& Oussii, A. (2013). Skills and attributes needed for success in accounting career: Do employers' expectations fit with students’ perceptions? Evidence from Tunisia. International Journal of Business and Management, 8(8), 118-132.

McDermott, E., Mangan, J., \& O’Connor, M. (2006). Graduate development programs and satisfaction levels. Journal of European Industrial Training, 30(6), 456-471.

McQuaid, R., \& Linda, C. (2005). The concept of employability. Urban Studies, 42(2), 197-219.

MdSaad, M., Robani, A., Jano, Z., \& Majid, I. (2013). Employers' perception on engineering, information, and communication technology (ICT) students’ employability skills. Global Journal of Engineering, 15(1), 42-47.

Murray, S., \& Robbinson, H. (2001). Graduates into sales-employer, student and university perspective. Education and Training, 43(3), 139-144.

Nasir, A., Ali, D., Noordin, M., \& Nordin, M. (2011). Nontechnical skills for technical skilled workers in Malaysia. Malaysia: Kuala Lumpur.

Ngoo, Y., Tiong, K., \& Pok, W. (2015). Bridging the gap of perceived skills between employers and accounting graduates in Malaysia. American Journal of Economics, 5(2), 98-104.

Pearson, R. (2001). Graduates: Work hard and be flexible. Brighton: The Institute for Employment Studies.

Rae, D. (2007). Connecting enterprise and graduate employability-challenges to the higher education culture and curriculum? Education and Training, 49(89), 605-619.

Ramadi, E., Ramadi, S., \& Nasr, K. (2015). Engineering graduates' skill sets in the MENA region: A gap analysis of industry expectations and satisfaction. European Journal of Engineering Education, 41(1), 34-52.

Ranasinghe, A., \& Herath, H. (2011). Employer satisfaction towards business graduates in Sri Lanka. International Conference on Social Science and Humanity, 5(6), 185 -189.

Rasul, M., Rauf, R., \& Mansor, A. (2013). Employability skills indicator as perceived by manufacturing employers. Asian Social Science, 9(8), 42-46.

Saad, M., \& Majid, I. (2014). Employers’ perceptions of important employability skills required from Malaysian engineering and information and communication technology (ICT) graduates. Global Journal of Engineering Education, 16(3), 110-115.

Salleh, R., Yusoff, M., Harun, H., \& Memon, M. (2015). Gauging industry's perspectives on soft skills of graduate architects: Importance vs satisfaction. Global Business and Management Research: An International Journal, 7(2), 95-101.

Ting, Sh., \& Ying, Ch. (2012). Is there a gap between practitioners' and academicians' perceptions on business graduates' competencies in Malaysia? Journal of Education and Vocational Research, 3(5), 167-172.

Yorke, M., \& Knight, P. (2006). Employability: Judging and communicating achievements. In Learning and employability series 1. New York, N.Y.: Higher Education Academy.

Yusof, N., \& Jamaluddin, Z. (2015). Graduate employability and preparedness: A case study of University of Malaysia Perlis (UNIMAP), Malaysia. Malaysian Journal of Society and Space, 11(11), 129-143. 